\title{
Patient perspective on coronary artery disease care
}

\section{Ksenija Tušek Bunc*}

Faculty of Medicine, University of Maribor, Maribor, Slovenia

\section{RECEIVED:}

July 28, 2015

ACCEPTED:

September 17, 2015

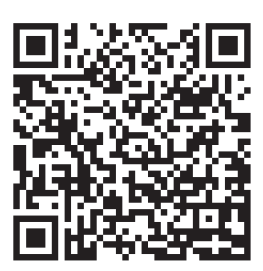

KEYWORDS: patients, coronary artery disease, assessment of chronic illness, quality of care. CITATION: Cardiol Croat. 2015;10(9-10):220-221. | DOI: http://dx.doi.org/10.15836/ccar.2015.220

*ADDRESS FOR CORRESPONDENCE: Ksenija Tušek Bunc, Department of Family Medicine, Faculty of Medicine, University of Maribor, Taborska 8, 2000 Maribor, Slovenia. / E-mail: ksenija.tusek-bunc@guest.arnes.si / Phone: +386-41-699-690

ORCID: Ksenija Tušek Bunc, http://orcid.org/0000-0003-1474-9090

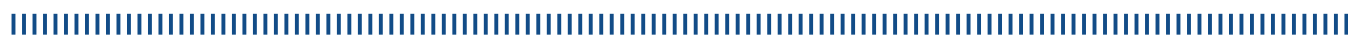

BACKGROUND: Patient's perspective of the management of their chronic disease better reflects the quality of care and offers health-care professionals more feedback. ${ }^{1,2}$

METHODS AND PATIENTS: The study was cross-sectional, included 423 patients with coronary artery disease. A comprehensive questionnaire for patients included the European Task Force for Patient Evaluation of General Practice (EUROPEP) instrument and the Patient Assessment of Chronic Illness Care (PACIC) questionnaire. To identify the number and types of data sets, factorial analysis and descriptive statistics were conducted on the PACIC questionnaire. To determine the correlation between the patient's assessment of the management of their chronic disease and the quality of care, the Pearson correlation coefficient was used.

TABLE 1. Descriptive information on the Patient Assessment of Chronic Illness Care (PACIC) items.

\begin{tabular}{|c|c|c|c|c|}
\hline Domains & Items & $\operatorname{Min}(\%)$ & $\operatorname{Max}(\%)$ & Mean (SD) \\
\hline \multirow{3}{*}{$\begin{array}{l}\text { Patient } \\
\text { activity }\end{array}$} & Asked for my ideas when we made a treatment plan. & 8.5 & 23.0 & $3.5(1.2)$ \\
\hline & Given choices about treatment to think about. & 9.6 & 26.5 & $3.5(1.3)$ \\
\hline & Asked to talk about any problems with my medicines or their effects. & 4.0 & 47.6 & $4.1(1.1)$ \\
\hline \multirow{3}{*}{$\begin{array}{l}\text { Delivery } \\
\text { system design/ } \\
\text { decision } \\
\text { support }\end{array}$} & Given a written list of things I should do to improve my health. & 14.1 & 25.9 & $3.3(1.4)$ \\
\hline & Satisfied that my care was well organized. & 2.0 & 38.9 & $4.1(0.9)$ \\
\hline & Shown how what I did to take care of myself influenced my condition. & 8.1 & 29.0 & $3.6(1.2)$ \\
\hline \multirow{5}{*}{$\begin{array}{l}\text { Goal setting/ } \\
\text { tailoring }\end{array}$} & Asked to talk about my goals in caring for my condition. & 11.4 & 20.8 & $3.3(1.3)$ \\
\hline & Helped to set specific goals to improve my eating or exercise. & 7.0 & 30.4 & $3.7(1.2)$ \\
\hline & Given a copy of my treatment plan. & 21.9 & 19.9 & $2.9(1.4)$ \\
\hline & Encouraged to go to a specific group or class to help me cope with my chronic condition. & 29.9 & 12.9 & $2.5(1.4)$ \\
\hline & Asked questions, either directly or in a survey, about my health habits. & 15.8 & 19.5 & $3.1(1.3)$ \\
\hline \multirow{3}{*}{$\begin{array}{l}\text { Problem } \\
\text { solving/ } \\
\text { contextual }\end{array}$} & $\begin{array}{l}\text { Sure that my doctor or nurse thought about my values, beliefs, and traditions when they recommended } \\
\text { treatments to me. }\end{array}$ & 4.3 & 39.3 & $4.0(1.1)$ \\
\hline & Helped to make a treatment plan that I could carry out in my daily life. & 11.6 & 28.9 & $3.5(1.3)$ \\
\hline & Helped to plan ahead so I could take care of my condition even in hard times. & 11.8 & 24.7 & $3.4(1.3)$ \\
\hline \multirow{6}{*}{$\begin{array}{l}\text { Follow-up/ } \\
\text { coordination }\end{array}$} & Asked how my chronic condition affects my life. & & & \\
\hline & Contacted after a visit to see how things were going. & 24.7 & 15.9 & $2.7(1.4)$ \\
\hline & Encouraged to attend programs in the community that could help me. & 29.0 & 7.9 & $2.3(1.2)$ \\
\hline & Referred to a dietitian, health educator, or counselor. & 37.2 & 9.4 & $2.2(1.3)$ \\
\hline & Told how my visits with other types of doctors, like an eye doctor or surgeon, helped my treatment. & 19.5 & 19.5 & $3.1(1.4)$ \\
\hline & Asked how my visits with other doctors were going. & 15.4 & 27.3 & $3.4(1.4)$ \\
\hline
\end{tabular}

SD = standard deviation; Min = response rate with the lowest score - Floor effect; Max: response rate with the highest score - Ceiling effect 
RESULTS: The average age of the participants was 68.0 years (SD = 10.8); 35.2\% were female. The average score for the entire PACIC (on a scale of 1-5) was $3.2(\mathrm{SD}=0.9$ ). The highest scores were for organizational aspects: organization of the practice (3.7), involvement of patients (3.7), and problem solving (3.5); the lowest score was for patient follow-up (2.7) (Tables 1, 2 and 3, Figure 1). The Pearson's correlation coefficient (Table 4) was $0.11(\mathrm{p}=0.034)$.

DISCUSSION: The PACIC questionnaire is a reliable tool for assessing the management of chronic diseases. The average PACIC score was higher than the average scores of patients with other diseases in other countries. The proportion of those with the highest and lowest scores (floor and ceiling effect) was comparable with a Dutch study. The quality of clinical care was positively correlated with the patient's assessment of that care, which may represent a new indicator of quality of care of chronic diseases.

TABLE 2. Descriptive analysis on the Patient Assessment of Chronic Illness Care (PACIC) domains (scale 1-5).

\begin{tabular}{lcc} 
PACIC domains & Mean & SD \\
\hline Patient activation & 3.7 & 1.06 \\
\hline Delivery system design/decision support & 3.7 & 0.99 \\
\hline Goal setting/tailoring & 3.1 & 1.02 \\
\hline Problem solving/contextual & 3.5 & 1.07 \\
\hline Follow-up/coordination & 2.7 & 1.09 \\
\hline Overall PACIC score & 3.2 & 0.91 \\
\hline
\end{tabular}

PACIC = Patient Assessment of Chronic IIIness Care questionnaire

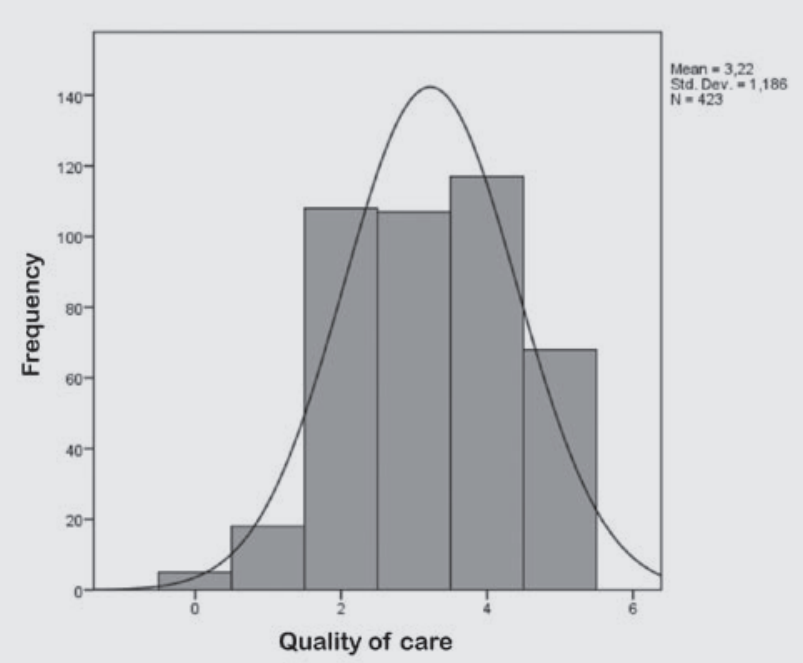

Items from 0 to 5 is the number of advice given and recorded in the past 15 months. Frequencies represent the number of patients who have received a certain number of tips and measures included in coronary patient care processes. The variable is distributed by the central peak.

FIGURE 1. Quality of coronary patient care - family doctor advice given and recorded.
Patient experience and involvement are essential to achieve better quality. In the future, further research is needed to accurately identify individual elements of the evaluation in strument.

TABLE 3. Quality of care of patients with coronary artery disease in the past 15 months.

\begin{tabular}{lcc} 
& $\mathrm{n}$ & $\%$ \\
\hline $\begin{array}{l}\text { Advice/contraindication physical activity } \\
\text { Dietary advice offered/recorded }\end{array}$ & 240 & 56.7 \\
\hline $\begin{array}{l}\text { Statin offered/recorded } \\
\text { Antiplatelet therapy, if not contra-indicated, }\end{array}$ & 367 & 86.6 \\
\hline $\begin{array}{l}\text { offered/recorded } \\
\text { Influenza vaccination }\end{array}$ & 93.8 \\
\hline
\end{tabular}

TABLE 4. Correlations between the Patient Assessment of Chronic Illness Care (PACIC) domains and quality of care and of coronary patients.

\begin{tabular}{lcc}
\hline PACIC Overall PACIC score & $r^{*}$ & $p$ \\
\hline PACIC Patient activation & 0.11 & 0.034 \\
\hline $\begin{array}{l}\text { PACIC Delivery system design/decision } \\
\text { support }\end{array}$ & 0.01 & 0.781 \\
\hline PACIC Goal setting/tailoring & 0.132 \\
\hline PACIC Problem solving/contextual & 0.10 & 0.044 \\
\hline PACIC S Follow-up/coordination & 0.10 & 0.049 \\
\hline
\end{tabular}

$*_{r}=$ Pearson's correlation coefficient; $P$ ACIC $=$ Patient Assessment of Chronic Illness Care questionnaire

1. Tusek-Bunc K, Petek-Ster M, Ster B, Petek D, Kersnik J. Validation of the Slovenian version of patient assessment of chronic illness care (PACIC) in patient with coronary heart disease. Coll Antropol. 2014;2:437-44. PubMed: http://www.ncbi.nlm.nih.gov/pubmed/25144971

2. Elwyn G, Buetow S, Hibbard J, Wensing M. Respecting the subjective: quality measurement from Respecting the subjective: quality measurement from the patient's perspective. BMJ. 2007;335:1021-2. DOI: http://dx.doi.org/10.1136/bmj.39339.490301.AD 